Why then is the rate of circumcision up to six times greater than the incidence of preputial disease? Analysis of the clinical findings in children referred for circumcision reported in this week's journal suggests a difference in interpretation of symptoms and clinical signs between surgeons and general practitioners (p 28)." Clearly confusion still exists about what constitutes "pathological" phimosis as distinct from "physiological" non-retractile foreskin. Most cases of pathological phimosis result from balanitis xerotica obliterans, while the remainder may be due to a different, distinct fibrotic disease. ${ }^{12}$ The underlying difficulty is the imprecision of the term phimosis. An important consideration is that balanitis xerotica obliterans usually develops after the age of 5 years. ${ }^{3}{ }^{10}$ The rarity of pathological phimosis under the age of 5 is an important observation since most circumcisions are performed before this age. ${ }^{10}$

Øster wrote in the introduction to his paper $^{2}$ that the publication of Gairdner's article nearly 20 years earlier seemed to have made no significant impression on clinical practice. ${ }^{1}$ Regrettably it seems that the same can be said more than 20 years after Øster's paper was published. A better understanding of the normal physiology, developmental anatomy, and pathology of the prepuce could prevent the removal of thousands of normal foreskins over the next 20 years.

ANDREW GORDON

Clinical Fellow

JACK COLLIN

Reader in Surgery

University of Oxford,

Nuffield Department of Surgery,

John Radcliffe Hospital,

Oxford OX3 9DU

1 Gairdner D. The fate of the foreskin. BMf 1949;ii:1433-6

2 Øster J. Further fate of the foreskin. Arch Dis Child 1968;43:200-3.

3 Rickwood AMK, Hemaltha V, Batcup G, Spitz L. Phimosis in boys. Br $\mathcal{O}$ Urol 1980;52:147-50.

Ratz JL. Carbon dioxide laser treatment of balanitis xerotica obliterans. 8 Am Acad Dermatol 1984;10:925-8.

Bale PM, Lochhead A, Martin HC, Gollow I. Balanitis xerotica obliterans in children. Pediatr Pathol 1987;7:617-27.

6 Escala JM and Rickwood AMK. Balanitis. Br 7 Urol 1988;63:196-7.

7 Fergusson DM, Lawton JM, Shannon FT. Neonatal circumcision and penile problem: an 8-year longitudinal study. Pediatrics 1988;81:537-41.

8 Stenram A, Malmfors G, Okmian L. Circumcision for phimosis: indications and results. Acta Paediatr Scan 1986;75:321-3.

Winberg J, Bollgren I, Gothefors L, Herthelius M, Tullus K. The prepuce: a mistage of nature? Lancet 1989;i:598-9.

10 Rickwood AMK, and Walker J. Is phimosis overdiagnosed in boys and are too many circumcisions performed in consequence? Ann Coll Surg Engl 1989;71:275-7.

1 Williams N, Chell J, Kapila L. Why are children referred for circumcision? BMf 1993; 306:28.

12 Clemmensen OJ, Krogh J, Petri M. The histologic spectrum of prepuces from patients with phimosis. Am f Dermatopathol 1988;10:104-8.

\title{
A counsellor in every practice?
}

\section{Reasons for caution}

Since Balint drew attention to the importance of counselling during consultation' ${ }^{\prime}$ general practitioners have been increasingly aware of the power of "the skilled and principled use of relationships to help the client develop self-knowledge, emotional acceptance and growth, and personal resources." As well as its general indications in anxiety, depression, and problems with relationships, ${ }^{3}$ counselling has been advocated for smoking cessation, ${ }^{4-7}$ modification of diet, ${ }^{48}$ alcohol misuse, ${ }^{910}$ postnatal depression, ${ }^{11}$ addiction to tranquillisers, ${ }^{12}$ and high risk sexual behaviour. ${ }^{13} 14$

Many attempts to evaluate its effectiveness have shown little or no benefit, ${ }^{5615-20}$ possibly due to methodological problems. ${ }^{21}$ When benefits have been claimed they have been small compared with the resources employed. Unsurprisingly, in the face of this evidence caution has been expressed: "Promoting a large counselling service in general practice before establishing what benefits accrue from this service is unwise." ${ }^{2324}$ Nor is it surprising that a discussion paper that extolled counselling while assuming its efficacy ${ }^{25}$ was greeted with some hostility. ${ }^{26}$

Despite the lack of convincing evidence of its efficacy many general practitioners believe in the value of counselling and of counsellors in general practice. ${ }^{2325}{ }^{27}$ As between $10 \%$ and $30 \%$ of consulting patients have mainly emotional problems ${ }^{27}$ the scope for increasing general practitioners' counselling skills $^{2829}$ or referring patients to an in house counsellor is substantial.

The main reason for general practitioners' enthusiasm for counselling may well be a desire to reduce contact with and responsibility for a very demanding group of patients. ${ }^{27}$ If this is so then increasing the counselling skills of general practitioners may be preferable to widening the primary health care team. Counselling requires, however, a move away from the authoritarian model of distance, diagnosis, and reassurance towards a model that recognises and promotes a person's autonomy. Many general practitioners may find this transition difficult.

Since 1990 the general practice contract has allowed reimbursement for the costs of employing counsellors. But the staffing budget is cash limited, and some practices may have to accept less than $70 \%$ reimbursement if their application is successful. Fundholding practices have more control over staffing, and many consider counsellors, along with physiotherapists and chiropodists, to be their highest priority.

Since the new contract was introduced another possibility has emerged. Many practices have applied to run health promotion clinics for managing stress, which are thinly disguised counselling sessions. The clinic fee is almost sufficient to cover a counsellor's sessional fee, thus costing the practice a minimal amount. The recently announced moratorium on new health promotion clinics has put a temporary brake on applications, but it seems probable that the new regulations from next April will encompass stress clinics, although within a cash limited total.

The stage therefore seems set for an explosion of counselling. Practices would be wise, however, not to appoint unqualified people just because they seem to have good listening skills. ${ }^{30}$ However well intentioned an amateur counsellor might be, there are profound professional, ethical, and clinical issues (not least confidentiality) that must be considered. In this issue Sibbald and colleagues show that fewer than half of counsellors have received specialist training in counselling. ${ }^{31}$

Counsellors should be accredited by the "Rugby conference" of the British Association for Counselling ${ }^{32}$ or be chartered psychotherapists recognised by the British Psychological Society. ${ }^{33}$ They should concentrate on non-directive counselling, ${ }^{2}$ being careful to avoid dictating solutions. ${ }^{34}$ They must keep accurate records, but the requirements of confidentiality may necessitate keeping some disclosures from the patients' doctors. (Some patients are not convinced that 
practice records remain confidential, while others fear that personal revelations may affect future relationships with their doctors.) They should have debriefing sessions with their own counsellor at least monthly and should have a commitment to audit and reaccreditation.

Some practices may balk at this degree of rigour, especially given the relative scarcity of trained counsellors. We would be wise, however, to move slowly. Every family health services authority should enter into discussions with its general practitioners to establish guidelines for the employment of counsellors. It is important that the current demand for counsellors does not lead to a lowering of standards and that all counsellors in primary care are properly trained, supervised, and supported.

MIKE PRINGLE

Senior Lecturer,

Department of General Practice,

Nottingham Medical School,

Nottingham NG7 2UH

Community Care Manager,

JOHN LAVERTY

Lincolnshire Family Health Services Authority,

Lincoln LN4 2HN

1 Balint M. The doctor, his patient and the illness. London: Pitman, 1964

2 Rowland $\mathrm{N}$. Counselling and counselling skills. In: Sheldon $\mathrm{M}$, ed. Counselling in general practice. London: Royal College of General Practitioners, 1992.

3 McLeod J. The work of counsellors in general practice. London: Royal College of General Practitioners, 1988. (Occasional paper 37.)

4 Mullen PD, Tabak ER. Patterns of counselling techniques used by family practice physicians for smoking, weight, exercise, and stress. Med Care 1989;27:694-704.

5 Sanders D, Fowler G, Mant D, Fuller A, Jones L, Marzillier J. Randomised controlled trial of antismoking advice by nurses in general practice. IR Coll Gen Pract 1989;39:273-6.

6 Slama K, Redman S, Perkins J, Reid ALA, Sanson-Fisher RW. The effectiveness of two smoking cessation programmes for use in general practice: a randomised clinical trial. BMF 1990;300: $1707-9$.
7 Townsend J, Wilkes H, Haines A, Jarvis M. Adolescent smokers seen in general practice: health, lifestyle, physical measurements, and response to antismoking advice. BMF 1991;303:947-50.

8 Murphy PS. Effect of nutrition education on nutrition counselling practices of family physicians. Acad Med 1989;64:98-102.

9 Shute PA. Patients' alcohol drinking habits in general practice: prevention and education fR Soc Med 1988;81:450-1.

10 Robertson C. Alcohol-a public health problem. Is there a role for the general practitioner? $\exists R$ Soc Med 1990;83:232-5.

11 Holden JM, Sagovsky R, Cox JL. Counselling in a general practice setting: controlled study of health visitor intervention in treatment of postnatal depression. BMF 1989;298:223-6.

12 Anderson S, Hasler J. Counselling in general practice. $7 R$ Coll Gen Pract 1979;29:352-6.

13 Holtedahl KA, Doumenc M, Steinert S, Roghell PK. Patients with sexually transmitted disease: a well-defined HIV risk group in general practice? Fam Pract 1991;8:42-7.

14 Clarke M. Sex and health promotion: the need for a new primary care initiative. $f R$ Coll Gen Pract 1987;37:555-6.

15 Ashhurst PM, Ward DF. An evaluation of counselling in general practice. London: Mental Health Foundation, 1983.

16 Martin E, Martin P. Changes in psychological diagnosis and prescription in a practice employing a counsellor. Fam Pract 1985;2:241-3.

17 Robson MH, France R, Bland M. Clinical psychologist in primary care. BMf 1984;288:1805-8.

18 Teasdale JD, Fennell MJV, Hibbert GA, Amies PL. Cognitive therapy for major depressive disorder in primary care. Br f Psychiatry 1984;144:400-6.

19 Earll L, Kincey J. Clinical psychology in general practice. $f R$ Coll Gen Pract 1982;32:32-7.

20 Cade J, O'Connell C. Management of weight problems and obesity: knowledge, attitudes and current practice of general practitioners. Br J Gen Pract 1991;41:147-50.

21 Corney RH. Counselling in general practice-does it work? $f R$ Soc Med 1990;83:253-7.

22 Waydenfeld D, Waydenfeld SW. Counselling in general practice. $₹ R$ Coll Gen Pract 1986;36:671-7.

23 Corney RN. Marriage guidance counselling in general practice. $f R$ Coll Gen Pract 1986;36:424-6.

23 Corney RN. Marriage guidance counselling in general practice. $\mathcal{F}$.

25 Rowland N, Irving J, Maynard A. Can general practitioners counsel? f $R$ Coll Gen Pract 1989;39: 118-20.

26 Shepherd S. Can general practitioners counsel? f R Coll Gen Pract 1989;39:304

27 Gray PG. Counsellors in general practice. $\mathcal{F} R$ Coll Gen Pract 1988;38:50-

28 Gonzalez-Willis A, Rafi I, Boekeloo M, Bowman M, Sardeson K, Taggart V, et al. Using simulated patients to train physicians in sexual risk assessment and risk reduction. Acad Med 1990;65:S7-8.

29 Rudner HL, Bestvater D, Bader E. Evaluating family counselling skills training for family practice. Med Educ 1990;24:461-6.

30 Nickless S, Mathers D, Fender E, Garner J. Appointing counsellors in general practice. Br f Gen Pract 1990;40:478.

31 Sibbald B, Addington-Hall J, Brenneman D, Freeling P. Counsellors in English and Welsh general practices: their nature and distribution. $B M \mathcal{1}$ 1993:306:29-33.

32 British Association for Counselling. Inviration to membership. Rugby: British Association for Counselling, 1989 .

33 Newman CV. Advice on the appointment of psychologists and counsellors within general practice. Br f Gen Pract 1990;40:388-9.

34 Stott NCH, Pill RM. 'Advise yes, dictate no'. Patients' views on health promotion in the consultation. Fam Pract 1990;7:125-31.

\section{Auditing $B M J$ decision making}

\section{We are setting targets and publishing how often we meet them}

This is the age of accountability, and editors of medical journals must be as accountable as anybody else. When bodies as diverse as hospitals, railways, schools, and dust carts are having to publish data demonstrating their performance, medical journals need to join in. Editors might argue that because we live in a highly competitive world in which authors, readers, and advertisers can all go elsewhere with ease we are already sufficiently accountable. But we can do better: we can set ourselves targets and then let readers know if we reach them.

We are setting ourselves targets for the time we take to make decisions on papers submitted to us and then to publish the papers. We aim to make a decision within eight weeks on papers that go through our full peer review process and within two weeks for the papers that we reject in house. Most papers should then be published within eight weeks of acceptance, although short reports, drug points, and lessons of the week may sometimes take longer. Starting in July, every six months we will publish our median time to make a decision and publish original papers and the proportion of cases in which we have met our targets.

To the many $B M \mathcal{F}$ readers who never submit a paper this may seem to be limited accountability, but the time that editors take to make decisions on publication is critical to authors. Borrowing an idea from the editors of the Annals of Internal Medicine, we have, in addition to setting targets for decision making and publication, developed what we call the "vital signs" of the BMF. These signs include data on circulation; the number of papers and letters submitted for publication, pages published, and advertisements placed; data from readers on which papers they read and what they like and dislike; citation data; "influence data" (like mentions of the $B M \mathcal{F}$ in parliament or the New York Times); and financial data. These data matter much more to us than they do to readers or authors, and so we don't plan to publish them regularly-unless readers tell us that they want them. For now we will restrict ourselves to data on decision making and publication times.

By the end of 1992 the $B M Y$ had received about 4350 papers and 3500 letters for publication during the year (exact data are not available because this editorial was written before Christmas). About half of the letters are published, usually without external peer review as we publish as letters only those that relate to matters raised in the journal within the past six weeks. "Out of the blue" letters are considered as papers and submitted to full peer review.

About half of the papers are rejected after being read by two editors without being sent for external peer review. Papers are rejected at this stage because they are insufficiently original for the $B M \mathcal{A}$, carry no useful message for a general medical audience, or are seriously flawed scientifically or completely incomprehensible. If we think we see even the glimmering of an original, important, and scientifically sound message then we will give authors the benefit of the doubt and send the paper to an external referee. We don't send more papers out to external referees because we don't want to exhaust this 